\title{
TESE
}

\section{Deleções do DNA Mitocondrial no Envelhecimento: Efeito da Disfunção na Fosforilação Oxidativa}

\author{
Célia Harumi Tengan
}

Resumo: Vários estudos descreveram o acúmulo de uma deleção do DNA mitocondrial (DNAmt), denominada de deleção comum, em tecidos pós-mitóticos durante o processo de envelhecimento. Esses achados levaram à hipótese de que radicais livres, gerados dentro da mitocôndria, poderiam lesar o DNAmt durante a vida normal. Acredita-se que um defeito no funciomento da cádeia respiratóra, decorrente da lesão do DNAmt, levaria a um aumento na produção de radicais livres, que por sua vez, lesariam o DNAmt, criando um ciclo vicioso é um fator importante no acúmulo de deleções do DNAmt, pacientes com deficiência da função oxidativa (independente do defeito primário) deveriam apresentar um acúmulo acelerado de deleções do DNAmt. Nós testamos esta hipótese através de três análises: (a) comparação dos níveis de deleção comum em controles normais e pacientes com doenças mitocondriais geneticamente caracterizadas e associadas com uma mutação do DNAmt; (b) análise da cosegregação da deleção comum (associada com o envelhecimento) com uma mutação de ponto patogênica do DNAmt; e (c) detecção de deleções múltiplas do DNAmt através de PCR (polymerase chain reaction) longo em controles e pacientes com doenças mitocondriais. Observamos uma correlação positiva entre a idade e níveis de deleção comum em controles $(r=0,80)$ e pacientes $(r=0,69)$. As inclinações das curvas eram semelhantes, sugerindo que a taxa de acúmulo da deleção comum associada com a idade era a mesma em ambos os grupos. Não conseguimos observar a co-segregação das moléculas de DNAmt contendo a mutação de ponto com a deleção comum e nem aumento no número de deleções em pacientes. Nossos resultados não suportam a hipótese de que o ciclo vicioso (lesão do DNAmt afeta a função da cadeia respiratória, levando a uma maior produção de radicais livres que, por sua vez, provocaria mais lesão do DNAmt) é um fator importante no acúmulo de deleções do DNAmt no processo de envelhecimento.

- Tese apresentada à Universidade Federal de Săo Paulo - Escola Paulista de Medicina para a obtençáo do Título de Doutor em Medicina em 1997.

Orientadores: Prof. Dr. Carlos Torres Moraes (Universidade de Miami) Prof. Dr. Alberto Alain Gabbai (UNIFESP) 


\section{Hemorragia Subaracnóidea, com Tomografia de Crânio sem Sinais de Sangramento: Aspectos Clínicos do Líquido Cefalorraquiano} Silvio Francisco

Resumo: Foram observados 23 casos de pacientes com suspeita clínica de hemorragia subaracnóidea (HSA), com tomografia de crânio (CT) sem sinais de sangramento, com diagnóstico definitivo realizado por exame de líquido cefalorraquiano (LCR). Os pacientes foram submetidos ao exame de CT em um período de 24 h a 15 dias após o início dos sintomas e no prazo não inferior a $12 \mathrm{~h}$ eram submetidos ao exame de LCR. Desses, 20 casos foram submetidos à angiografia cerebral. Estabeleceu-se a classificação clínica de Hunt \& Hess.

$O$ estudo demonstrou os seguintes achados: 1) distribuição dos pacientes segundo sexo e idade com predomínio do sexo feminino na quinta e sexta década de vida; 2 ) um terço dos pacientes apresentaram intervalo de tempo entre o ictus e a realização da CT e do LCR entre 24 e $48 \mathrm{~h}$, período de maior sensibilidade da CT; 3) não houve correlação estatística entre o número de hemácias e: a presença de aneurisma, topografia dos aneurismas e classificação clínica dos pacientes; 4) o índice de xantocromia de maior expressão no LCR foi de 0,$5 ; 5)$ dos pacientes estudados com angiografia cerebral, $55 \%$ tiveram o diagnóstico de aneurisma com predomínio no território de carótida e cerebral anterior; 6) o grau clínico dominante foi Hunt e Hess I e II.

Todos os achados encontrados demonstraram a necessidade da realização de LCR em suspeita de HSA sem sinais de sangramento na CT.

\footnotetext{
- Tese apresentada à Universidade Federal de Sảo Paulo - Escola Paulista de Medicina, para obtençăo do Título de Mestre em Neurologia em 1996.
}

Orientador: Prof. Dr. João Baptista dos Reis Fllho Co-orientador: Dr. Afonso Carlos Neves 